REVISTA ANDALUZA DE ANTROPOLOGÍA.

NÚMERO 5: APORTACIONES Y POTENCIALIDADES DE LA ANTROPOLOGÍA DE LA SALUD.

SEPTIEMBRE DE 2013

ISSN 2174-6796

[pp. 12-34]

http://dx.doi.org/10.12795/RAA.2013.i05.02

Fecha de Recepción: 19-04-2013

Fecha de Aceptación: 22-06-2013

\title{
EL FACTOR CULTURAL COMO HERRAMIENTA TERAPÉUTICA. A VUELTAS CON EL MODELO BIOMÉDICO EN LA ATENCIÓN SANITARIA
}

To Dr. David Mackenzie, Scholar

\section{MARCIAL GONDAR PORTASANY \\ Universidad de Santiago de Compostela}

\section{Resumen.}

Partiendo de la nula capacidad de los actuales clínicos para tener en cuenta la dimensión cultural de la enfermedad, lo que voy a hacer en el que sigue es tratar de argumentar cómo, al lado de las herramientas técnicas, el factor cultural y lingüístico también puede y debe ser utilizado como herramienta de curación. Se proponen estrategias sacadas del Marketing y de la Pragmática que son de aplicación en la relación médico-paciente, de suerte que se mejore notablemente el rapport entre ellos y, de esta manera, se potencie la eficacia del acto curativo.

Palabras clave: Antropología médica aplicada, logoterapia, Marketing social, herramientas de la seducción, modelos médicos, medicina preventiva.

\begin{abstract}
.
Given the current failure of clinicians to take into account the cultural aspect of the disease, what I'll do in the following is to argue as, next to the technical tools, the cultural and linguistic factor can and should be used as a healing tool. This paper suggests the use of techniques employed in Marketing and Pragmatics that can be applied in the
\end{abstract}


doctor-patient relationship, thereby greatly improving the rapport between them and enchancing the efficiency of the healing process.

Keywords: Applied medical Anthropology, logotherapy, social Marketing, tools of seduction, medical models, preventive medicine.

Si en la relación médico-paciente el clínico desconoce el contexto cultural en el que son usadas las palabras que ambos utilizan, correrá el riesgo de entenderlas al revés o, sin más, no entenderlas en absoluto. Un ejemplo sacado de la práctica sanitaria puede valerme para explicitar lo que pretendo afirmar. En una Sesión Clínica de Psiquiatría donde se estaban revisando los casos que los miembros del equipo habían tenido que atender por la mañana, un psiquiatra en prácticas narraba así su experiencia:

-Esta mañana me llegó una señora de X [un municipio rural] y, después de contarme su historia, yo la vi tan de libro que ya le dije: "Señora, lo que le pasa a usted es que tiene una ansiedad tremenda".

Ella, sin dejarme ni casi acabar, me espetó:

-iAy, señor, no! ¡Ansia es lo que a mí me falta!

En la cultura campesina gallega, de donde estoy tomando la etnografía para esta reflexión, cuando se dice de alguien que "es muy ansioso" o "tiene ansia", supongamos, por el trabajo, se está diciendo que es una persona activa, buscadora de vida, etc. Esto es, lo contrario de lo que la etiqueta clínica de "ansiedad" está expresando. Aquel joven psiquiatra, a pesar de hablar en gallego con sus pacientes, desconocía su contexto cultural.

Hecha esta precisión, voy a entrar ya en materia, intentando justificar cómo la lengua y la cultura de un pueblo pueden ser utilizadas como instrumento terapéutico y, de esta manera, recuperar aquella logoterapia en la que era tan experta la medicina de nuestros padres y abuelos.

Lo que voy a hacer en el que sigue es tratar de argumentar cómo, al lado de las herramientas técnicas, el factor cultural y lingüístico también puede y debe ser utilizado como herramienta de curación. Y digo el por qué.

En los últimos años, con el desarrollo de la bioquímica y de la tecnología, la medicina da un salto de gigante que hizo posible solucionar problemas que los médicos de hace bien pocos años no se habrían atrevido ni siquiera a sospechar. Con todo, hay tres ámbitos en los que las cosas no caminan con la misma velocidad:

-El de la cronicidad, donde la ansiedad creciente del enfermo al ver que aquello no se acaba nunca, termina por descolocar al médico.

-El de la gestión del paciente terminal. Poco más allá llegamos que a las Unidades de dolor.

-El de la Medicina preventiva, en la que, por más que no estemos siendo conscientes, más que prevención, generamos culpabilidad. 
Por limitarnos a este último factor, quizás el más preocupante, y, aunque haremos más tarde un desarrollo más extendido del tema, séame permitida una pequeñísima anticipación tomando el caso concreto de la propaganda antitabaco: "El tabaco produce cáncer", "El tabaco mata", "El tabaco genera impotencia"... Démonos cuenta de que con sentencias como esta, en vez de ir a las raíces de la adición y tratar de mudar las condiciones que llevan a ella o, por lo menos, procurar un substituto funcional no patógeno del placer de fumar, nos limitamos a culpabilizar a quien fuma, aguardando que el miedo y la culpa actúen de "descolgadores" del hábito.

El problema está en que los humanos no cambiamos de actitudes en función de miedos o de culpas ("Mata", "Perjudica a los que están a tu alrededor", etc.); esto lo único que hace, si se da el caso, es inducir angustia (Gondar, 2005 (61): 18-20). Cambiar de actitud implica poner en acción determinados circuitos emotivos que con este tipo de propaganda ni se tocan. Dejo aquí el tema solo enunciado y tornemos al hecho del fracaso.

Las causas fundamentales de este relativo revés en los tres ámbitos que estoy considerando creo que son dos:

-La fuerte deshumanización de la práctica médica que tuvo lugar en los últimos tiempos.

-La no menos fuerte medicalización de la gestión de la enfermedad que hace aparecer la Medicina como la nueva religión de nuestros días con sus mandamientos, con sus castigos y con la consiguiente culpabilización sobre los pacientes.

\section{LA DESHUMANIZACIÓN DE LA PRÁCTICA MÉDICA}

Como todo el mundo sabe, en un período de relativamente pocos años, pasamos de aquellos viejos médicos de cabecera que curaban más con la mano en el hombro del paciente que con las sulfamidas a un nuevo tipo de sanador que se reduce a ser un apéndice de las máquinas.

Cuando un paciente visita a su médico para hacerle una demanda, si el sanador estima que la cosa no tiene importancia, va a despacharlo con cualquier solución de trámite pero basta que sospeche de algo más grave para que la respuesta sea:

- Vamos a hacer una analítica.

Cuando esto sucede, el enfermo puede dejar de hablar; hasta que vengan los resultados de los análisis, sus palabras para el médico van a ser poco más que ruido (Grimberg, 2006. 179). Entre los muchos problemas que tal conducta genera, no es el menor la ruda simplificación a que se somete el dolor. En la epistemología médica actual, aquello de lo que se queja un paciente es significativo si refleja un estado fisiológico; si no se detecta tal referente empírico la propia significación de la queja se pone ya en tela de juicio. Tales quejas, v.g. las del dolor crónico, a menudo son consideradas como un reflejo de las creencias del paciente o de estados psicológicos que, caso de no tener base en un trastorno 
fisiológico, el médico tiene una fuerte tendencia a meterlas en el continente de lo no real, salvo que, por liberarse del incordio, decida "desviarle" la demanda al psiquiatra.

La terapia por la palabra de los viejos clínicos (ahí están los análisis de Laín Entralgo o de Marañón para verificarlo) deja lugar al silencio. La palabra sólo se utiliza para comunicar, no ya para curar. Los médicos de hoy actúan como fontaneros o como mecánicos porque los enfermos son vistos como tuberías o, si se prefiere, como coches que tienen un problema en el motor. Esto acontece con todos los médicos en general; hasta los psiquiatras que siempre llevaron una trayectoria distinta dando a la palabra una importancia fundamental, a medida que la investigación farmacológica avanza, también se van haciendo amigos del silencio.

Esta forma de actuar que, cuando se trata de la fase aguda de la enfermedad, funciona más o menos razonablemente, no tiene el mismo éxito cuando hay que gestionar la cronicidad y, mucho menos aún, la fase terminal de la enfermedad. En estos casos el médico no sabe mucho qué decir ni qué hacer; si acaso desviarles el "paquete" a las enfermeras y a los familiares. Reducir los contactos al mínimo y sacarse al paciente de delante es lo único que se le ocurre.

Nos vamos a preguntar, ¿de dónde viene esa incapacidad para la palabra que lleva al médico a huir de sus pacientes? Como señaló B. Good ya en 1990 en las Lewis Henry Morgan Lectures de Rochester que después sistematizó en Medicine, Rationality and Experience y, desde entonces, es ya un tópico establecido en la Antropología de la salud, la cosa viene derivando de cómo fue la educación de los futuros sanadores en las facultades de Medicina. Desde los primeros años de formación, al aprendiz de médico se le educa para ver al ser humano de forma distinta a cómo lo hacen el resto de los mortales. Toda la formación que recibe va encaminada a enmascarar la dimensión existencial y humana del enfermo, a reducirlo a un hecho natural o, para ser más preciso, bioquímico. Para llegar a formar parte de esa nueva cultura, el neófito debe aprender a ver, escribir y hablar de una forma particular (Good, 1994: 65-87).

Ver

Frente a la visión totalizadora de la percepción común, el neófito debe aprender a ver por partes:

-En el laboratorio de anatomía aparecen las piezas del cadáver trochado.

-A través del microscopio y de las diapositivas va a poder observar los tejidos, llegando a zonas cada vez más pequeñas.

-Más no remata ahí la descomposición y despiezamiento del cuerpo enfermo. Todavía nos queda reducirlo a sus componentes bioquímicos y moleculares, donde los curadores van a situar el auténtico "obiectum morbidum". 


\section{Escribir}

Cuando al neófito se le enseña a hacer una Historia clínica, no se le enseña a describir el estado vital de una persona sino a cómo convertirla en caso, esto es, en algo abstracto, desencadenado de su situación existencial. Es más, de su estado solo se considerará aquello que tiene en común con las tipologías médicas y sus variantes. Como es fácil ver, lo que se consigue con esto es que, como señala Byron Good, el pathos se convierta en patología.

\section{Hablar}

Cuando presenta a sus colegas una Historia clínica, el médico utiliza herramientas sacadas de la retórica para persuadir a su audiencia. Como cualquier autor, está representando un papel, y no tiene empacho en eliminar, cuando no inventar o remodelar datos para que la historia que se discute en la sesión quede más redonda y consistente.

El problema radica en que de toda esta manipulación que fue sufriendo durante su formación, el clínico no tiene apenas conciencia. Fue convertido de ciudadano en técnico pero es incapaz de ver que las historias, en este caso la historia clínica, no representa sin más a la realidad sino que está construida desde determinados esquemas de ideas, valoraciones y, hasta, sobreentendidos que, sin darse cuenta, él mismo fue introduciendo en ella.

¿Que cuáles son esos perjuicios y sobreentendidos? En el caso de la medicina estrictamente biologicista, el sobreentendido más importante es el de la sustitución del mundo de la vida y de su racionalidad por una razón solo instrumental donde no tiene ningún lugar la pregunta por el sentido de las cosas.

Cuando, después de andar entre cadáveres y laboratorios, se encuentra con enfermos reales, el nuevo médico descubre que, además de tener cuerpo, los enfermos aman, temen, desean, fantasean, se agobian... Pero él no fue preparado para gestionar esa parte de la persona y, en vez de reconocerlo, opta por el silencio y por pensar que esa parte del ser del paciente no pertenece a la medicina sino a otras ramas del saber o del creer.

De lo que no cae en la cuenta es de que, con esa actitud, se está desaprovechando un operador terapéutico de primera magnitud: la palabra. Es un paso atrás en la historia de la Medicina. El boom tecnológico-bioquímico, como un gran tsunami, arrasó con toda esa habilidad con la logoterapia en la que los sanadores de antes habían llegado a ser maestros.

Séame permitido, recurriendo a algunas experiencias clínicas, presentar algunos ejemplos de los que ese viejo modelo, hoy olvidado, podría dar de sí:

-Un emigrante, procedente del rural gallego, que, aprovechando su período de vacaciones, hacía una demanda psiquiátrica narraba así su caso. Estaba trabajando en Ginebra en una fábrica de chips para computador y se encontraba bien hasta que, son sus palabras, "ya no pude hacer lo que yo quería, tengo que hacer lo que me 


\section{manda el chip".}

-Otro emigrante, también de origen rural, que trabajaba cuando hace la consulta como cocinero en un superpetrolero, después de explicar su caso (también, falta de control sobre sus propias acciones) remataba así su historia tratando de buscar la etiología de su problema: - "ya me dijo un médico que lo que a mí me pasa es que se me metió dentro un sistema nervioso que me tiene escarajado".

Como es sabido, en la cosmovisión tradicional gallega existe la creencia de que los espíritus de los muertos, el demonio, las meigas, etc., se meten en el cuerpo de las personas de suerte que, cuando esto pasa, ya no son ellas las que controlan su obrar sino el espíritu que llevan dentro.

Aquellos dos pacientes estaban convencidos que de dar tales explicaciones al médico iban a ser considerados como paletos y atrasados; lo que ellos hicieron fue mistificar esas creencias arcaicas mudándolas por algo que ellos consideraban tan moderno como el chip y el sistema nervioso. Conviene tener muy en cuenta que no se trata de que, movidos por la voluntad de disimular delante del médico, intenten disfrazar sus verdaderos sentimientos, la traducción a la mentalidad moderna se lleva a cabo de modo espontáneo a nivel subliminal sin que ellos tengan la más mínima conciencia del proceso. Lo que pretendo subrayar es que vestir de "Adolfo Domínguez", vale decir, adoptar hábitos y actitudes plenamente modernos, para nada equivale a que la arquitectura de la cabeza, la forma de pensar y de sentir, sea también la propia de la modernidad.

Si somos conscientes de que implicar al enfermo en su mal desde el primer momento de la terapia, de suerte que se sienta protagonista de la misma, es fundamental para el éxito, y esto hay que hacerlo desde una etiología que para él tenga sentido (ese "-y, entonces, doctor, lo mío de donde viene derivando"- con el que interrogan al curador sobre la causa de su mal), entenderemos lo necesario que es que el diagnóstico sea elaborado teniendo en cuenta la cosmovisión del paciente.

En la misma clase lógica de las narrativas anteriores hay que ubicar otras dos historias, estas ya fuera del contexto clínico de la sala de consulta:

Una hija, al ver que su padre se está pasando un poco en la ingesta de alcohol le pregunta:

-Pero, papá, ¿el médico no le sacó el vino?

El padre responde de inmediato:

-¡Sí, mujer, pero este es de casa!

La que sigue es una historia de taberna en la que el que escribe fue protagonista. Tomando unos vinos en la taberna de una aldea y sabiéndome el que me acompañaba interesado en estos temas de la salud, me interpeló de este modo:

-No sé si Vd. lo sabe pero jel cerdo de casa no tiene colesterol!

-"Pues, Vd. dirá", le respondí.

-"Mire, yo como mucho cerdo y mi hija siempre me anda diciendo: -Papá, tiene que 
ir a mirar el colesterol que usted come mucho cerdo. Tanto me jodió la cabeza que terminé por ir. ¡Oiga, ni un gramo!"

La historia remataba:

- "Pero, eso sí, iyo no como más que cerdo de casa!"

Historias de este tipo, como la del "vino de casa", del que cualquier paisano está convencido que tiene "tres grados menos que el agua" y no como esos "pinarejos que joden la cabeza", demuestra lo inútil que es lanzar cualquier tipo de campaña para luchar contra el alcoholismo sin tener en cuenta la particular cosmovisión, valores y creencias de los que van a ser sus destinatarios. Algo que para los viejos curadores constituía su práctica diaria.

Lo que, quizás, la clase médica de hoy conoce poco es que esas técnicas de sus antepasados que ellos desprecian por obsoletas fueron retomadas por los actuales técnicos de Marketing para ponerlas al servicio de las grandes plataformas comerciales y de ciertos tipos de política.

Para entrar en este territorio, me voy a referir a un hecho que nada tiene que ver con la salud y sí con la política de los EEUU en los últimos años. Hasta la reciente victoria de Obama, el Partido Demócrata se encontraba bastante perdido al ver que, elección tras elección, los conservadores eran quienes se llevaban el gato al agua mientras ellos quedaban con un palmo de narices.

La reflexión que los perdedores hacían era, más o menos, la siguiente: que las clases bienestantes voten a Mr. Bush y a su gente tiene toda la lógica del mundo en cuanto que la política que estos promueven es la que les beneficia pero ¿cómo explicar que los segmentos sociales más despojados voten también en conservador?

Con la espina de esta pregunta y con ocasión de las penúltimas elecciones a Gobernador de California llevaron a cabo la siguiente experiencia: organizaron un "Grupo de control" de doce personas formado exclusivamente por potenciales votantes en las inminentes elecciones a Gobernador pero compuesto todo él por electores pertenecientes a los estratos sociales más bajos, auténtico lumpenproletariat, y con él realizaron una única y breve sesión.

La sesión constaba de dos partes. En la primera parte, la más larga, se explicaba el Programa político de los Demócratas para el Estado de California y, a continuación, el de los Republicanos. Cada uno de ellos era presentado por un militante activo de los respectivos partidos que no podía asistir a la explicación de su contrincante. Una vez rematadas las exposiciones, la pregunta que tenían que contestar los miembros del Grupo de control era la siguiente: -¿Cuál de estos dos programas, piensas tú que deja más satisfechos tus intereses? La respuesta mayoritaria (casi consiguió el 93\%) fue: -El Demócrata

La segunda parte de la sesión fue todavía mucho más breve. Se le preguntaba directamente "A quien piensas votar? Los candidatos eran en aquella ocasión, por parte de los 
Demócratas "Gray" Davis y por parte de los Republicanos Arnold Schwarzenegger, el conocido actor. La respuesta, prácticamente igual de mayoritaria que la anterior pero con un sorprendente cambio de sentido fue: - "A Schwarzenegger".

El resultado de la experiencia parece apuntar a que la gente no toma sus decisiones, al menos las políticas, por ideología ni siquiera por interés propio. La pregunta que los politólogos demócratas americanos se hacían era: -¿Por que vota, entonces, la gente?

Para ir abriendo camino en este complejo mundo de las conductas, de las tomas de decisión y en los cambios de actitud de las personas, particularmente en el campo de la salud aunque no exclusivamente, séame permitida una historia que casi todos los días se hace real en los consultorios médicos de Atención Primaria. Supongamos que cualquiera de nosotros tiene una tos no demasiado fuerte pero que no termina de pasar. Si la cosa se prolonga por un tiempo largo, es bastante probable que, una mañana decidamos enfrentarnos a la preocupación e ir al médico. Al contarle nuestro caso, con casi total seguridad, nos va a preguntar: - ¿Tú fumas? Si le decimos que sí, y no tiene demasiados clientes en la sala de espera, la respuesta va a ser un muy documentado discurso sobre los efectos negativos del tabaco en nuestro cuerpo y las consecuencias que con altísima probabilidad nos aguardan de no cortar de cuajo con ese hábito.

Sigamos suponiendo que tan contundente fue el parlamento del médico sobre nuestro caso que, para tratar de serenarnos un poco de la intranquilidad que nos metió en el cuerpo, decidimos entrar en el bar más próximo para tomar un café. De suceder nuestra historia antes de la actual ley auspiciada por la ministra del ramo, es bastante probable que, casi como un acto reflejo, echásemos mano al bolsillo, cogiésemos el paquete de tabaco y nos pusiésemos a fumar al tiempo que seguíamos con nuestro café. Como puede apreciarse, el médico no tuvo mucho éxito práctico con su erudito y largo discurso, excepto la impresión inicial.

Estando así en la barra del bar con el cigarro en la boca y el café en la taza, nos viene a la cabeza la urgencia de que esa misma tarde debemos ir a comprar determinadas cosas que precisamos al Corte Inglés. Y hasta decidimos hacer, cosa no muy frecuente, una lista con aquello que nos es tan necesario. Vamos a imaginar que en nuestra lista iban tres cosas. Puedo garantizar al lector o lectora, porque ahí están los estudios de Marketing para confirmarlo, que, si se comporta como la mayoría de los mortales de este llamado "primer mundo", esa tarde, del Corte Inglés, no va a salir con menos de nueve cosas.

La pregunta que ahora nos vamos a hacer es: ¿Por qué el médico no consiguió convencernos de algo que tan bien nos venía y, en cambio, el Corte Inglés fue quien de vendernos lo que para nada precisábamos?

La respuesta está en que el médico, para convencernos de que aceptar su posición era lo mejor para nosotros utilizó la "razón" mientras que el Corte Inglés para atraernos a lo que a él le interesaba echó mano de la "seducción". El Corte Inglés sabe, y, como él, cualquiera que conozca los rudimentos del Marketing, que los humanos (excepto cuando 
nos movemos en los niveles más superficiales de la personalidad) no cambiamos las conductas tanto por la vía de los argumentos como por la de las emociones. El médico, en cambio, está convencido de que dándonos razones de por qué no debemos hacer unas cosas y sí hacer otra, una vez que el destinatario de sus argumentos entienda los motivos, va a cambiar de actitud adoptando la postura "razonable".

Es preciso pararse a reflexionar un momento sobre este "mal camino" del médico porque para nada adoptó una conducta atípica sino que está instalado en una de las más profundas tradiciones de la cultura ilustrada occidental ya desde los tiempos de la Grecia clásica. En uno de los Diálogos de Platón, ese su personaje, Sócrates, siempre tan tozudo para encontrar respuestas, se pregunta:

-¿Qué es un criminal?

Después de una cierta perplejidad y dudas del auditorio, él mismo se responde:

-Un ciudadano mal informado.

El convencimiento que late en Platón cuando hace dar esta respuesta a su Sócrates es que si a un criminal le explicamos cómo debe comportarse correctamente, una vez que entienda nuestras razones dejará de ser un desviado social para convertirse en un ciudadano comme il faut.

No acabó esta manera de pensar en la Grecia de Platón, en nuestro mundo actual, continuamos con los mismos perjuicios. Pensemos en un hecho tan cotidiano en nuestras pueblos y ciudades como puede ser el botellón y los trastornos de todo tipo que lleva consigo. En los momentos más calientes del conflicto, con seguridad, aparecerán voces reclamando mayor actividad policial y castigos duros para los culpables pero también no va a faltar quien insista en que no es buen camino acallar los síntomas sino que se hace preciso acudir a la raíz del problema y esta no es otra que la educación de los jóvenes desde su más tierna infancia. Si la voz ilustrada no se queda en la diagnosis sino que se atreve también con el tratamiento, muy probablemente hablará de la necesidad de meter ya en el curriculum de la Educación primaria alguna materia en la que se reflexione sobre este tipo de desórdenes.

Si el desorden fuese de otro tipo, imaginemos, esas conducciones alocadas y sin normas de las que, con tanta frecuencia, somos espectadores, cuando no actores, en nuestras carreteras volverán a aparecer las dos reacciones anteriores. Junto a la del remedio autoritario, la del ciudadano ilustrado que aboga por la solución de introducir en la mochila escolar del niño una materia nueva. Esta vez, una "Educación vial".

Nuestros ciudadanos ilustrados de hoy, en la misma línea del que pensaba el viejo Platón, están convencidos que a través de la educación entendida como discurso, vale decir, como encadenamiento de argumentos sobre los distintos tópicos, es posible ir guiando y mudando los hábitos y conductas de las personas, especialmente si lo hacemos desde pequeños. Sería bueno que comenzásemos a caer en la cuenta de que tal modelo educativo no lleva muy lejos, excepto en lo que se refiere a generarles a los chavales serios 
problemas de cervicales fruto de esas desaforadas mochilas de libros con que cargan a toda hora.

Comenzaré, con una vieja historia de antropólogos, justificando estas afirmaciones. Un hombre de ciencia intentaba explicar a un caníbal que su sociedad y su cultura eran muy superiores porque no se practicaba en ellas el canibalismo. El indígena, que había oído hablar mucho de las sociedades occidentales, después de los argumentos del hombre blanco, estaba ya a punto de aceptar la maldad del canibalismo pero preguntó: ¿Qué hacen los blancos con tanta carne humana como queda disponible después de cada guerra? Cuando el hombre de ciencia intentó explicarle que mataban a la gente pero no la comían, el caníbal se sintió confundido y, pese a las explicaciones del blanco, no consiguió comprender lo absurdo de este comportamiento.

En muchos ámbitos de la vida humana la racionalidad no es más que una ilusión. Lo que prima es la emoción por más que muchas veces disfrazada con la máscara de lo racional porque lo que sí hay en nuestra cultura de hoy es una necesidad muy fuerte de aparecer como racional no solo ante uno sino, sobre todo, ante los demás. La fábula de la zorra de Esopo que, cuando ve que no puede alcanzar las uvas, abandona la parra comentando “están verdes" se repite en mil escenarios de nuestra vida.

Es muy difícil sustraerse a la conspiración de las emociones. Cuando estas imponen su hegemonía en el psiquismo humano, es difícil que la razón consiga mantener el control. De nada sirve que en la terraza de un rascacielos se le diga a quien tiene vértigo a las alturas que puede mirar tranquilamente hacia abajo porque hay barandas protectoras muy resistentes. De nada sirve al que ha de cruzar un precipicio que se le haga ver que el tablero es muy ancho. Si el tablero estuviera colocado sobre el suelo, aunque fuese mucho más estrecho, cruzaría sin dificultad el precipicio. Los argumentos racionales nada pueden cuando lo que tenemos que gestionar es una pulsión emotiva intensa. Seguimos creyendo, como los griegos de antes, que para cambiar la forma de comportarnos debemos mudar de forma de pensar y esto no es así; la gente no actúa en función de criterios racionales ni siquiera en función de sus propios intereses. Y esto lo sabe muy bien el Corte Inglés por eso se comporta como se comporta.

¿Por qué no nos representamos las cosas de esta otra manera? ¿Por qué el personal sanitario para gestionar la salud de sus pacientes no puede utilizar las mismas técnicas que utiliza el Corte Inglés para conseguir vendernos lo que no precisamos para nada? ¿Por qué no podemos recuperar las viejas técnicas de la palabra en las que tan versados eran los viejos sanadores?

\section{LA GRAMÁTICA DE LA SEDUCCIÓN}

Para hacerlo así, solo tendríamos que caer en la cuenta de que precisamos deshacernos de unos pocos perjuicios sobre el poder absoluto de la Razón o, para ser más precisos, deberemos descubrir que junto a la Gramática de la comunicación racional, funciona 
otra gramática que vamos a llamar de la seducción y que, cuando se trata de orientar las conductas de las personas, es, sin duda, bien más eficaz. Lo que voy a hacer a continuación es presentar los presupuestos de que parte esta Gramática de la seducción.

El punto de partida de este instrumento pasa por tomar conciencia de que la mayor parte de los mensajes que recibimos y emitimos (las dos terceras partes) no son conscientes sino subliminales.

Una buena parte de quienes lean este texto, seguramente tienen permiso de conducir $\mathrm{y}$, sin duda, todos y todas fueron muchas veces en un coche. Me voy a permitir hacer a quien lea la siguiente pregunta: ¿Para dónde corre el cuentakilómetros cuando el coche va marcha atrás? Es casi seguro que a más de un lector o lectora le va a entrar la duda a la hora de dar una respuesta. El motivo de esta inseguridad deriva de que, cuando el coche está dando marcha atrás, con muy buen criterio por otra parte, quien conduce está mirando por la luneta o por el espejo retrovisor para no dañar el vehículo $\mathrm{y}$, sin embargo, el cuentakilómetros sigue allí marcando. La moraleja que me interesa sacar de esta historia es que una buena parte de la información que recibimos pasa por nosotros sin que tan siquiera nos demos cuenta.

No solo es que tendamos a no percibir mucha de la información que recibimos, muchísimas veces tampoco somos conscientes de la que estamos dando a los demás. Me voy a servir de una historia para ilustrarlo. Imaginad que en un viaje a la India decidís comprar una de esas bonitas piedras de Jade que a tan buen precio allí se consiguen. En vez de dirigiros al vendedor directamente que está allí en la calle con su pequeña mesita, vais a hacer algo antes. Con discreción, mirad el precio que les piden por la misma pieza a otros compradores que van pasando antes que vosotros. Lo primero que detectaréis es que, de entrada, no se le da a todos el mismo precio. A unos les va a pedir más y a otros menos por más que la pieza sea la misma. Tratando de buscar una razón, quizás penséis que unos le caen más simpáticos que otros a quien vende. No hay tal. Cuando nosotros tenemos interés en algo, nuestra pupila se dilata, cuando nos produce malestar, se contrae, cuando ni una cosa ni otra, nuestra pupila sigue como estaba. El vendedor, que está entrenado en esta técnica, simplemente con mirar a los ojos del potencial comprador, decide el precio de entrada en función del interés de quien compra. De verle un interés escaso, ajusta al máximo el precio para no perder el cliente. De lo contrario, de entrada sube el precio porque, como cualquier vendedor sabe, "para bajar siempre hay tiempo". Como es fácil darse cuenta, la eficacia del proceso radica en que la mayor parte de los que por allí pasan no tienen la más mínima conciencia de la información que le están dando al vendedor. No se trata de un caso particular; como dije hace un momento, los seres humanos estamos continuamente dando información sobre nosotros, solo es preciso saber descifrarla.

Una última consideración respeto de la información subliminal. No solo damos y recibimos información sin que, la mayor parte de las veces, ni nos demos cuenta, además, 
cada uno de nosotros sabe un buen puñado de cosas sin que tampoco tengamos la más mínima conciencia temática. Me gustaría recordar quien lea aquella comedia de Molière, "El burgués gentilhombre", en la que su protagonista, M. Jourdain, llega a rico y se siente en el deber de mejorar su nivel cultural; contrata a un preceptor y este, lo que le enseña el primer día es a distinguir la prosa del verso. Cuando consigue enterarse de lo que es la prosa, M. Jourdain comenta asombrado:

$\neg$ “AAnda, y yo toda la vida hablando en prosa y sin saberlo!

Deja de sonreír por la chuscada del nuevo rico y repara con seriedad en su descubrimiento porque nos puede estar pasando a nosotros lo mismo; es más, seguro que nos está pasando. M. Jourdain sabía hablar en prosa, pero no caía en la cuenta de que lo sabía. Todos los niños conocen las reglas de la gramática antes de que se las enseñen en la escuela. La prueba es que el niño concuerda perfectamente sujeto, verbo y predicado. Quiere esto decir que, a más del aprendizaje consciente, la cultura posee otra forma de transmitirnos mensajes que tienen como característica especial la de no darnos cuenta de que se nos están transmitiendo. Mi intento ahora va ser apuntar, aunque sea en un mínimo esbozo, algo sobre estos mensajes ocultos que llegan sin que nos enteremos. Siendo más preciso, llegan a nosotros y nos influyen o, por mejor decir, nos manipulan, sin que tengamos la menor idea de este influjo. Para eso, una vez que presenté el nicho epistemológico en el que se instala, vamos a ver una de las reglas más importantes con que funciona esta Gramática de la Seducción.

El lenguaje de la seducción, o vía emotiva, tiene una forma de actuar que se mueve en las antípodas de la argumentación que es lo que caracteriza la vía racional, tan del gusto del pensamiento ilustrado. Su principal regla es que no utiliza la comunicación consciente (como hace la vía racional) sino la comunicación subliminal.

Consiste esto en que cuando parece que estamos haciendo otra cosa, como por ejemplo divirtiéndonos, en realidad nos están manipulando. Un caso concreto, sacado de la literatura popular gallega, me va a permitir ilustrar lo que intento decir. Voy a comenzar por esa estrofa que todo gallego conoce y que suena así:

Ojos verdes son traidores,

azules son mentirosos,

los verdes y acastañados

son firmes y verdadosos.

Si yo hubiese preguntado ¿Qué es esto?, se me diría, con razón, que es un cantar. Y si continuase preguntando ¿para qué se canta?, con la misma razón, se me podría responder que: para divertirse, para pasarlo bien, fruto de ese cierto nivel de alcohol en sangre después del cual ya viene "Asturias, patria querida", etc.

Vamos ahora a mirar esa misma estrofa pero no ya con los ojos inocentes del juerguista sino con la sospecha y el cuidado de quien no quiere comulgar con ruedas de molino. Es preciso, en primer lugar, no olvidar que la literatura popular, a diferencia de la mayoría 
de la culta, no se agota en la estética y en la estilística, sino que acostumbra a ser siempre literatura de combate, esto es, arma arrojadiza que nos sirve para atacar o defendernos, en una palabra, para andar por la vida. No es, pues, posible analizar la literatura popular sin tener en cuenta su conexión con la realidad, su contexto de uso.

A la búsqueda de ese contexto, nos vamos a preguntar ¿cuál es el color de ojos dominante en la población gallega? Los datos sobre pigmentación de ojos en Galicia señalan que algo más que dos tercios de los gallegos y gallegas tienen los ojos oscuros mientras que los colores claros no llegan a afectar ni siquiera al treinta por ciento de la población.

Guardando este dato biológico en la memoria, vamos a presentar ahora un problema de teoría económica. Las relaciones entre chicos y chicas desde el punto de vista del atractivo físico, los "ligues", están sometidos a las leyes del mercado y, de modo particular, a la más importante de todas ellas, a la ley de la oferta y de la demanda. Quiérese decir, acontece a los "ligues" lo que a los pimientos de Padrón. Cuando, al final de la primavera, llegan los primeros, la producción aún es escasa y la gana de probarlos grande, ¿qué va a pasar? La respuesta es fácil: poca oferta, mucha demanda, los precios se disparan. Si, en cambio, nos encontramos al final del verano, cuando la producción es mucha y ya vamos yendo hartos de pimientos, la situación es la contraria: mucha oferta, poca demanda, los precios caen por los suelos. Aplicando la misma forma de razonar a este particular mercado que son las relaciones de moceo, siempre y cuando el resto de las características de la persona, naturalmente, sean más o menos homogéneas ¿quién jugará con ventaja? Obviamente, el poseedor o poseedora del bien escaso, en este caso, los ojos claros. Si el experimento lo hubiéramos hecho en un país nórdico, donde lo claro es lo dominante, la situación sería exactamente la contraria, basta pensar en la magia que para una nórdica tiene el amante latino, moreno y de ojos negros.

Como puede verse, si se me permite una cierta exageración, la situación atenta al principal de los derechos humanos: el de no ser tenido en menos frente a otro ser humano por razones de biología pero, no por eso, la ley de hierro de la competencia deja de cumplirse, una pequeña parte juega con ventaja frente a la gran masa de la población que resulta discriminada.

¿Cómo se defiende la mayoría agraviada? Pues..., con un cantar que proclama unos mensajes muy claros y pertinentes al caso: ¿ojos verdes?, preciosos pero "traidores", ¿azules?, fantásticos, maravillosos, pero "mentirosos". Si lo que se quiere no es algo inconstante y engañoso como la hermosura sino permanente y seguro, entonces, la opción es clara: negros y acastañados, que son firmes y verdaderos.

¿Verdad que parece que esta lectura no pasa de ser una broma sin capacidad alguna para convencer a nadie? Si no queremos valorar a la ligera la situación, debemos reparar en dos cosas. La primera es que nadie de los que cantan la copla o de quien la escucha tiene la más mínima conciencia de que se les esté tratando de convencer de nada. La sensación que todos tienen es que estamos, simplemente, divirtiéndonos y pasándolo bien. La 
segunda es que la copla no hace ningún tipo de razonamiento, ningún tipo de argumento con el que se pretenda justificar las sentencias que se emiten. Como se ve, estamos delante de afirmaciones sin prueba alguna; poca cosa, a primera vista, para convencer a nadie. Y digo, con plena conciencia, a primera vista porque bajo esta apariencia tan débil, está presente una de las grandes vías que utiliza la comunicación persuasiva: la propaganda subliminal.

Frente a casos como el de nuestro médico anti tabaco que tejía una ristra de argumentos para establecer las conexiones causales entre unos hechos y otros y, de este modo, hacer que el paciente llegue a una conclusión, quien, en cambio, utiliza la vía de la seducción, con el simple hecho de colocar una cosa del lado de la otra, produce en el observador la impresión de que una cosa produce la otra.

Me atrevería a decir que cualquiera de nosotros tuvo, o conoce de cerca, experiencias como la que voy a contar. Supongamos que estamos a las puertas de un examen complicado y estamos más que convencidos que va a resultar un fracaso. Tiene lugar el examen y, contra nuestro pronóstico, los resultados fueron magníficos. Aquel día llevábamos puesta una determinada chupa, o la falda roja, o el BIC que acabábamos de comprar para el examen. Olvidamos la historia hasta que, un tiempo después, volvemos a estar en una situación parecida. Más de uno o de una de quienes se ven en esta situación, medio en broma medio en serio y como quien no quiere la cosa comenta:

-"voy a volver a llevar aquella chupa (o falda, o lo que sea) que tanta suerte me dio en el examen anterior".

Si nos paramos un poco a pensar, vemos que estamos en el pensamiento mágico donde lo semejante produce lo semejante. Escribí con ese bolígrafo y me salió bien el examen, luego si vuelvo a hacer el examen con el mismo bolígrafo me tendrá también que salir bien. No tiene lógica, es verdad, pero no pensemos que esto solo funciona con mentes "prelógicas", "primitivas", "crédulas" o "paletas", está en la estructura básica de todo ser humano de cualquier época o cultura, por eso el Marketing no para de utilizar esta estrategia.

Estos mensajes de que estoy hablando consisten en deslizar impresiones de modo tal que el cerebro no sea quien deba filtrarlas y racionalizarlas, lo que, obviamente, no quiere decir que no sea capaz de percibirlas.

La utilidad de la vía emocional se basa en que, a diferencia de lo que ocurre cuando utilizan con nosotros la vía racional, nuestra razón no se defiende creando un contraargumento o, en todo caso sopesando las razones que nos están dando. Si se destaca que un producto es barato, de inmediato puede surgir la sospecha de que no sea demasiado bueno. Si yo trato de vender lo que digo que es una magnífica cámara digital por diez euros, aquel a quien intento vendérsela a fe que me va a decir o, cuanto menos, pensar: - “Seguro que es buena!”, o bien: - ¿Dónde la robaste?”; la Razón es el gran escudo que tenemos los humanos para defendernos. La ventaja de las apelaciones emocionales es 
que no crean contra-argumentos, entre otras cosas porque nadie se defiende cuando no piensa ser atacado. Recordemos que los mensajes que verdaderamente interesan cuando utilizamos este camino discurren todos por vía subliminal.

Seguro que más de un lector o lectora se estará preguntando como es posible que yo esté defendiendo este ataque brutal a la Razón, sobre todo cuando estamos hablando de algo tan serio como la salud. Soy perfectamente consciente del valor de la razón, lo único que pretendo decir es que, si no somos capaces de meter nuestro discurso racional dentro de un envoltorio que les resulte seductor a aquellos a quien pretendemos convencer, la eficacia de nuestro mensaje corre un fuerte riesgo de no ser atendido. No se trata, pues, de descartar la Razón de nuestra práctica sino, solo de envolverla en un atractivo "packing". Un ejemplo me valdrá para concretar mejor mi tesis. Si yo le preguntara a quien lea estas líneas:

- ¿A qué se aprende jugando al Monopoly?”

Seguro que me contestaría algo así como:

- “A ser un especulador" o - "A mirar con buenos ojos la especulación”.

De hecho, el objetivo final de cada participante en el juego no es otro que el de arruinar a los restantes jugadores.

Supongamos que quisiese llevar a un determinado colectivo a reflexionar críticamente sobre este fenómeno de la especulación y a ofrecerle estrategias y herramientas de análisis. Yo podría hacer esto utilizando la vía de la razón desnuda, esto es, construyendo un discurso a través de una retahíla de argumentos sobre el tema o bien, como acabo de decir, empaquetando la razón en seducción. ¿Qué tengo que hacer para utilizar esta segunda vía? Una posibilidad es diseñar un Monopoly distinto en el que, junto al papel de especulador, fuera posible que hubiese jugadores que desempeñasen otros roles de naturaleza bien distinta. Las reglas de este nuevo Monopoly exigen que cuando el jugador "especulador" quisiera poner un hotel o varias casas en una determinada calle tiene que llegar a un acuerdo con otros que están desempeñando el papel de miembro de un colectivo ecologista, de una comunidad de vecinos, del colegio de arquitectos o de cualquier otro papel sobre el que nos interesara trabajar el incremento de conciencia crítica. A esto es a lo que llamo "empaquetar" la razón. Se trata de generar un contexto (en este caso lúdico, pero pudiera hacerse activando cualquiera otra emoción) que resulte seductor para las personas sobre las que se quiere actuar y, subliminalmente, ir introduciendo en él los mensajes o actitudes que se desea potenciar.

Tomemos ahora un problema del campo de la salud. Hace ya algún tiempo colaboré con un equipo de salud mental del SERGAS (Servicio Galego de Saúde) que tenía a su cargo la atención psiquiátrica de un municipio rural gallego vecino a la ciudad donde este radicaba. Para evitar la situación de "descoloque" que provocaba en los pacientes rurales esta "emigración" sanitaria a la ciudad, el equipo decidió desplazarse ("emigrar") allí dos veces por semana. Los que antes eran percibidos por los terapeutas como 
pacientes individuales pasaron a ser vistos como miembros de un colectivo con muchas características compartidas.

Desde esta mirada "holista" pudo detectarse que dos de los síntomas sanitarios más importantes que el grupo tenía eran: una tasa de suicidio infanto-juvenil mucho más alta de lo normal y una igualmente alta tasa de "somatizaciones" (transformación inconsciente de una afección psíquica en orgánica) en la gente mayor (Kleiman, 1980:147). El acelerado cambio social totalmente no planificado del mundo rural gallego en los últimos tiempos está provocando que los jóvenes construyan su mundo sin pautas y apenas contacto con los mayores y, por otro lado, que los viejos vean cómo las ancestrales estrategias de control familiar que utilizaban dejan de ser eficaces y pasan a ser considerados trastos viejos (carcas, carrozas, reaccionarios, etc.) e incluso una molestia y una carga para la familia. Unos y otros viven de espaldas, ahogados en sus propios problemas y sin tener nada que decirse. Si en esta situación el viejo se quejase de lo abandonado que se siente, sabe perfectamente que iba a ser tachado de persona insoportable; el camino que escoge es quejarse de algún malestar físico porque es bastante probable que la reacción sea:-“El viejo está enfermo". El joven, a su vez, en situación parecida de angustia y frustración, va a optar por el lenguaje de las drogas, la violencia, el suicidio, etc.

En casos como estos, el diagnóstico es claro. El mundo fracturado y autista en que cada grupo vive está en la raíz de muchas de las "descompensaciones" que padecen. La solución también es clara: hacer que pasen de vivir de espaldas a entender que unos saben unas cosas y otros otras, pueden compartir sus experiencias y sus vidas y, de esta forma, enfrentarse en mejores condiciones a la situación "descompensadora” que les toca vivir.

Para llevar este objetivo a la práctica, el terapeuta puede seguir dos caminos. Uno, en el estilo del médico que pretendía desenganchar a su paciente del tabaco, consistiría en hacer ante los jóvenes un razonado discurso con el que trata de convencerlos de lo inadecuado de sus conductas, otro, en el que, utilizando las técnicas de la gramática de la seducción, cree escenarios en los que se le transmita esta misma idea a través de la comunicación subliminal. Mientras con el primer formato solo conseguirá aburrir a sus oyentes y que estos huyan despavoridos, con el segundo tiene posibilidades de llevarlos a buen puerto.

En esta segunda línea de acción, lo que nosotros hicimos fue: ponernos en contacto con algunos profesores del colegio local al que muchos de los jóvenes asistían y, explicándoles la idea, proponerles que hiciesen a los alumnos interesados la siguiente pregunta: - ¿Os gustaría escribir y publicar un libro en el que solo vosotros fueseis los autores?” El único pié forzado que tenía la propuesta era que el libro debía tratar de cómo era la vida en el pueblo donde vivían cuando sus abuelos eran de su misma edad (cómo se divertían, como trabajaban, como "ligaban", etc.).

Con esta propuesta, los informantes privilegiados y casi únicos eran los abuelos y sus 
pares de edad. Los que hasta ahora eran aburridos, pesados y "pelmas" pasaban a ser colaboradores necesarios e insustituibles si los jóvenes verdaderamente querían realizar el objeto de su deseo. Los viejos, por otra parte, acostumbrados a ver cómo sus nietos "pasaban" de ellos, se veían, de repente, acosados por ellos y siendo interrogados a todas horas. Todo ese mundo nuevo y desconocido que los jóvenes iban descubriendo fue, poco a poco plasmándose en el libro. Lo que a los conductores e inspiradores del trabajo nos preocupaba no era tanto la exactitud del relato ni que por el medio apareciesen incluso poesías de Lope de Vega convertidas en romances populares sino el cambio en las relaciones entre unos y otros (y con él la mejora de la salud mental comunitaria) que con la experiencia se fue consiguiendo.

Cuando el libro estuvo impreso, aprovechando un día de asueto ( $O$ día das Letras galegas), se hizo una fiesta en el colegio en la que, en medio de pinchos, bebidas y música, un escritor gallego muy conocido, presentaba el libro de los jóvenes autores a los padres y abuelos de los alumnos (los nombres de los informantes figuraban en el libro) junto con la prensa y los políticos a los que también se había convocado. A las familias de los que habían participado de una u otra manera, a los políticos y a los medios se les dio un ejemplar como recuerdo del acto con lo que la pequeña edición, bastante casera porque los fondos eran pocos, quedó totalmente agotada.

Cuando llegaron en verano los emigrantes y tuvieron noticia del hecho, querían hacerse con un ejemplar en el que se contaban las viejas historias de su pueblo y, lo mismo, muchas de las familias que no disponían de ejemplar (algunos se decían dispuestos a pagar "lo que fuese"). Además, no fueron pocos los mayores que encontraron imprecisiones e inexactitudes en el texto y querían corregirlo. Una librería local, que vio en la historia un pequeño negocio, se manifestó dispuesta a hacer una segunda edición. El equipo redactor asumió la tarea de corregir errores e incluso hacer algunos añadidos, se publicó la edición revisada y un pequeño pueblo no especialmente aficionado a la lectura vio como también esta segunda se agotaba. Aquel no era "un libro", era "su libro".

Sin gastar un céntimo en psicofármacos, sin ninguna yatrogenia hepatotóxica, sin medicalizar ni angustiar a la ciudadanía, estábamos en camino de mejorar el bienestar del pueblo dando pasos hacia una medicina preventiva de nuevo cuño. Un terapeuta al uso no le llamaría a esto medicina, para nosotros, en cambio, el reto es ir rompiendo este prejuicio.

\section{LA MEDICALIZACIÓN ABUSIVA DE LA SALUD}

Hablé al comienzo de la incapacidad de la medicina actual para utilizar la "palabra", y particularmente la seducción, y de las dificultades que de esta carencia se siguen a la hora de gestionar el malestar y, de modo especial, la cronicidad y la enfermedad terminal. Pero también comentaba al inicio que un tercer campo en el que no se acaba de descubrir el camino correcto era el de la Medicina preventiva y esta dificultad de avance, decía, que 
había que ponerla en relación con la fuerte medicalización de la salud a la que estamos asistiendo y, por qué no decirlo, provocando.

Hasta hace muy pocos años, la gestión de la enfermedad se llevaba a cabo dentro de la propia comunidad de modo que el enfermo nunca perdía el contacto con el grupo familiar y de amistad al que pertenecía.

Antiguamente esta integración había sido aún más intensa: la gestión de la enfermedad la llevaba a cabo el propio grupo social al que pertenecía el enfermo. Eran los entendidos y las entendidas locales (curanderos o curanderas, magos y brujas, personas habilidosas, etc.) quienes diagnosticaban y aplicaban los remedios que les parecían pertinentes. Cuando no sabían como enfocar el problema, colocaban a la persona enferma en un cruce de caminos aguardando que algún viajero que pasara por allí supiera cómo hacerlo. Así como en todas las casas siempre había alguien que tenía conocimientos de herrero, de albañil o de cantero (o si no, en la casa del lado) así pasaba con las enfermedades; eran, sobre todo, las mujeres las que conocían los remedios para tratarlas $\mathrm{y}$, si no bastaba, se acudía a los especialistas locales. En el tiempo de nuestros abuelos y, para algunos, de nuestros padres, en el mundo no urbano, aún seguían también muchas de estas cosas.

Cuando la Medicina se convierte en una profesión especializada y aparece el médico, este vive en la propia comunidad. Los no especialmente jóvenes de hoy aún conocimos al viejo médico de cabecera que se desplazaba a la casa del enfermo cuando era reclamado. Las ventajas eran obvias. La angustia que toda enfermedad produce en el paciente y en sus familiares más cercanos quedaba mitigada por el calor humano que conlleva el sentirse en un mundo conocido (Kleiman, 1991:197). El hospital, como el asilo, no eran espacios de atención normal sino de acogida y ayuda para personas pobres y marginadas. Con la disculpa de la tecnología, de la asepsia y de la eficiencia, las cosas cambiaron totalmente hoy en día. Cuando alguien cae enfermo, el médico trata, si puede evitarlo, de no venir a casa; tiene el enfermo que desplazarse al Centro de Atención Primaria o a Urgencias y, si la cosa se considera importante, debe ingresar en el hospital.

Desde el punto de vista psicológico, las descompensaciones son muchas:

-Deja de ser una persona para pasar a convertirse, pongamos por caso, en un 15/ no sé cuántos (su número de la Seguridad Social).

-Lo sacan de su mundo, le hablan en un lenguaje que apenas entiende; en una palabra, se convierte en un emigrante sanitario con unas vivencias descompensadoras muy parecidas a las del emigrante económico cuando tiene que desplazarse a una tierra extraña.

-Los parientes y vecinos deben limitar sus contactos con él a las horas de visita.

-Las preguntas que suscita la angustia del paciente reciben unas respuestas sui generis, etc., etc.

La disculpa más utilizada para justificar estos inconvenientes pasa por argumentar que con los escasos minutos de que se disponen en el sistema público de salud incluso 
para una primera consulta, se hace imposible ese trato personalizado por el que abogo (Lindembaum, 1993:142). Como respuesta a esta dificultad, me gustaría comentar un hecho. En una zona rural de Galicia donde un equipo de Psiquiatría con el que colaboro intenta incorporar esta Medicina de la palabra de la que estoy hablando, también trabajan varios curanderos tradicionales. ¿Sabe el lector o lectora, que cantidad de tiempo emplean ellos para una primera consulta en los momentos de más afluencia de clientes (sábados y domingos)? Tres minutos y medio. Y puedo asegurar que el nivel de rapport que consiguen entre cliente y "saudador" es extraordinario. Lo que viene a decir que una buena relación médico-paciente no está en función de la cantidad de tiempo que se emplea en la misma sino de cómo se gestiona ese tiempo. La pregunta es obvia, ¿por qué no podemos utilizar nosotros esas mismas técnicas, que, por otra parte, no son otras que las de la Gramática de la seducción de que antes hablé?

Pero, retomemos el argumento que venía desarrollando. Todo lo dicho anteriormente hace que, durante el tiempo de su enfermedad, el paciente no sea más que un mero cuerpo, aislado de su mundo, del que se espera que de la menor lata posible (- “Limítese a estar enfermo!", oí una vez contestar a una enfermera a un paciente que la acosaba con sus preguntas en un hospital). El papel de enfermo ya no es el papel de un ser humano sino lo de un mero cuerpo averiado. Y cuando salga fuera, si la enfermedad dejó secuelas, le harán un plan de vida que se aguarda que siga religiosamente.

El enfermo crónico no sólo es arrancado de la sociedad para el hospital, cuando lo devuelven no va a ser ya más una persona normal, pertenece a la cofradía del régimen de vida sano.

Pero esta religión de la salud no solo busca adeptos entre los enfermos, pretende que toda la sociedad se convierta a ella. Nace así una de las ramas de la Medicina con más auge social: la Medicina preventiva.

Antes había dos fases en la vida de una persona:

-Cuando estaba sana y disfrutaba.

-Cuando estaba enferma y lo pasaba mal.

Ahora sigue habiendo dos fases:

-Cuando está enferma, (y continúa pasándolo mal).

- Cuando puede estar enferma.

Fruto de esa propaganda medicalizadora de la salud, cada vez hay más gente a la que no le duele nada pero está preocupada por cómo tendrá el colesterol, la tensión, los triglicéridos y veinte mil cosas más.

Y se preguntará quien lea: - ¿es mala esa preocupación? Los clásicos decían “in medio, virtus", "la virtud está en el medio". Nuestros paisanos gallegos, hablando de cómo tratar a los animales, aconsejan: - "Ni tanto jarre! que huya, ni tanto ¡xooo! que se pare". Lo que es malo no es la preocupación, lo malo es que esa preocupación se convierta en una obsesión, y eso es, justo, lo que está pasando. La salud se está convirtiendo en la nueva 
religión de nuestro tiempo, estamos medicalizando, psicologizando y psiquiatrizando a la sociedad. Estamos convirtiendo la salud en obsesión (Correa Urquiza, 2010: 262-286). No es una boutade lo que estoy diciendo. Basta pararse a pensar en cómo se está promocionando la "cultura de la salud" para caer en la cuenta de que se están utilizando los mismos medios que siempre usaron las religiones para hacer cautivas a las conciencias. Reconocimientos, screenings, analíticas de control, dietas, ingesta, etc. están formuladas como los mandamientos de una religión: ¡no matarás!, ¡no robarás!, ¡no desearás la mujer de tu próximo!, etc. Y no perdamos de vista que las religiones con mandamientos fomentan dos cosas graves: obsesión y culpabilidad.

En esta construcción de la obsesión y de la culpa, la Medicina preventiva, siguiendo los pasos de la religión, llega, si no a inventar enfermedades (que, a veces también, véanse los estudios sobre "disease mongering", vid.: Payer, 1992; Ruíz-Cantero \& Cambronero, 2011, etc. ), sí a magnificarlas y a convertirlas en estigmas.

La iglesia católica dice que inventó la Inquisición para perseguir a las brujas y a los herejes. La verdad fue más bien la contraria, las brujas fueron un invento de los inquisidores. Basta para comprobarlo, repasar el proceso que la Inquisición sigue, a finales del XVI, contra la vecina de Cangas de Morrazo, María Soliña. Esta mujer, hija y esposa de pescador, con la cultura que en la época tenían las mujeres de su clase, acusada de brujería, cuando el Inquisidor le pregunta: - ¿No es verdad que tuviste relación carnal con diablos íncubos $y$ súcubos? (¿cuántos lectores de hoy entienden la pregunta?) responde: -Sí, muchas veces. Es preciso pensar si algo parecido no estaremos haciendo hoy con el colesterol, con las fibromialgias, con los trastornos bipolares y con todas esas etiquetas cajón de sastre que las modas médicas van imponiendo. Un ejemplo: el Sr. Arturo, un vecino de una aldea del valle de la Maía, se siente absolutamente discriminado al ver que una buena parte de las personas de su edad están siendo tratadas con Sintrom, un anticoagulante, mientras él, por mucho que se lo demanda a su médico de cabecera, no consigue que le prescriban este tratamiento. - ¿Y por qué, si a todos le dan el Sintrom, yo no tengo derecho a esa cosa? Para acabar, nos vamos a preguntar: ¿Se puede hacer algo frente a esa divinización de la Medicina preventiva? Sí, desmedicalizar lo más posible la enfermedad.

Una historia concreta puede valer como ejemplo de lo que entiendo por desmedicalizar los problemas de salud. En una ocasión, un grupo de vecinos de una muy pequeña aldea rural perteneciente al sector que atiende la Unidad de Salud Mental con la que colaboro solicitó que se le impartieran unas charlas sobre salud mental. En la demanda no había mayor precisión. En vez de aceptar o rechazar sin más las charlas, el equipo decidió desplazarse al lugar. En la aldea, una de tantas aldeas gallegas, la situación por la que estaban pasando sus vecinos era absolutamente deprimente. La antigua vida social tan intensa había sido sustituida por un intenso y triste autismo donde las familias habían perdido esa alegría que da la vida en común. La propuesta que se le hizo desde la Unidad fue: por qué no hacer, en lugar de las charlas, un periódico de la aldea elaborado por ellos 
mismos que actuarían a modo de Consejo de redacción.

Les pareció bien la propuesta y, cada quince días, se juntaban miembros del equipo y los vecinos del lugar para decidir los contenidos y la elaboración del periódico que salía una vez al mes. En cada reunión, se trataban aquellos temas que ellos juzgaban interesantes al tiempo que se compartían vino, tortillas, chorizos o lo que fuese que los miembros del grupo aportaban a la reunión. El interés de la experiencia no estaba tanto en los contenidos del periódico como en la satisfacción y bienestar que proporcionaba al grupo ese cemento social del convivir. Lo que al principio era un grupo desestructurado, se iba convirtiendo poco a poco en una comunidad que se sentía satisfecha de sí misma.

Sin tocar para nada temas de salud, lo que se estaba llevando allí a cabo era una auténtica Medicina preventiva en la que sin acudir a culpas, dietas y demás parafernalia de la Medicina preventiva al uso, se conseguía un estado de bienestar sin angustia que es lo que debe constituir el punto de partida de la auténtica prevención. Esto es lo que entiendo por medicina desmedicalizada.

La estrategia del periódico no sólo tuvo efectos en la salud comunitaria de la aldea. En una de esas juntas comunitario-periodísticas, al proponerles el día para la siguiente reunión, dijeron que no podía ser en esa fecha porque (era época electoral) los de no recuerdo que partido habían solicitado ese día para el meeting. La propuesta que se le hizo desde el equipo de salud fue: - ¿Y qué os parece si, en vez de escuchar lo que esa gente quiera decir, no hacemos un listado de los problemas que tenemos aquí y les preguntamos qué alternativas ofrecen para solucionarlos?” Así se hizo y, cuando llegó el día, antes de que los políticos empezasen a hablar, uno de los miembros del colectivo se levantó para preguntarles qué soluciones se comprometían a aportar. La satisfacción del equipo de salud está en que no solo estábamos en el bueno camino para construir una comunidad sana sino que, al tiempo, era también crítica y consciente de sus derechos.

Si somos capaces de situarnos en este camino alternativo, no solo estaremos contribuyendo a disminuir la obsesión y la culpabilidad sino que estaremos incrementando la sensación de normalidad y la alegría de vivir. Pero es que, a mayores, habremos también ahorrado recursos que podremos utilizar para atender mejor a las auténticas necesidades sanitarias. Posiblemente, en esta altura de la reflexión, algunos de los que leéis os estaréis preguntando: ¿pero este tipo de trabajo que aquí se propone no cae fuera del que le compete al personal sanitario? ¿No es, más bien, cosa de asistentes sociales, antropólogos y profesionales de ese tipo?

No dispongo de tiempo para meterme ahora en este tema. Solo recordar aquello que las señoras burguesas de antes recomendaban a sus hijas cuando las preparaban para el matrimonio: -Hija mía, recuerda que si tú no sabes hacer las cosas, tampoco sabrás mandárselas hacer a quien trabaje contigo.

Como conclusión de este paseo por esta forma alternativa de analizar y planificar la gestión de la salud y, de manera particular, la relación médico-paciente, me parece de 
interés destacar dos cosas:

El modelo que aquí se propone es esencialmente aplicado (learning by doing). Quiere esto decir que no se debe entender como un "protocolo" teórico-normativo que en un segundo momento se lleva a la práctica. La profunda irreductibilidad de las distintas historias clínicas hace que las reglas, más que como guías, hay que entenderlas como estímulos para que el terapeuta descubra la solución mejor en cada caso.

La demanda del neófito que pretende iniciarse en este campo y pregunta: -¿Qué puedo leer sobre este enfoque? no tiene respuesta fácil. La utilización del Marketing social y de la Pragmática en el campo de la relación médico-enfermo está en sus comienzos por lo que apenas hay una literatura especializada (más allá de los discursos programáticos) con la que poder comparar las experiencias propias y, todavía menos, con programas de training en este campo (vid.: Martínez Hernaez, 2006; Correa Urquiza, 2010; Devereux, 1985). El único camino razonable pasa por irse formando en el campo del Marketing y de la Pragmática tratando de adaptar las técnicas a la problemática de la gestión de la salud y entrar en contacto con equipos de terapeutas que sientan la necesidad de iniciar caminos alternativos de este tipo con los que intercambiar experiencias. 


\section{REFERENCIAS BIBLIOGRÁFICAS}

Correa Urquiza, Martín (2010) Radio Nikosia: la rebelión de los saberes profanos (otras prácticas, otros territorios para la locura). Tesis doctoral, Universitat Rovira i Virgili. Devereux, Georges (1985) Ethnopsychanalyse complémentariste. Paris: Flammarion. Gondar, Marcial (2005) "Neoliberalismo e saúde mental. Economía política da loucura". A Trabe de Ouro: (61): 13-29.

Good, Byron (1994) Medicine, Rationality and Experience: An Anthropological Perspective. Cambridge: Cambridge Universiy Press.

Grimberg, Mabel (Ed.) (2009) Miradas antropológicas sobre la salud, la enfermedad y el dolor crónico. Buenos Aires: Antropofagia.

Kleiman, Arthur (1980) Patients and Healers in the Context of Culture. California: University of California Press.

Kleiman, Arthur (1991) Rethinking psychiatry: from cultural category to personal experience. New York: Free Press.

Lindembaum, Shirley (1993) Knowledge, Power and Practice: The Anthropology of Medicine and Everyday Life (ComparativeStudies of Health Systemser Medical Care). California: University of California Press.

Martínez Hernáez, Angel (2006) "Cuando las hormigas corretean por el cerebro. Retos y realidades de la psiquiatría cultural". Cadernos de Saúde Pública/PublicHealthReports, 22(11):2269-2280.

Payer, Lynn (1992) Disease-mongers : how doctors, drug companies, and insurers are making you feel sick. New York: Wiley\&Sons.

Ruíz-Cantero, Maria Teresa \& Cambronero-Saiz, Belén (2011) "La metamorfosis de la salud: invención de enfermedades y estrategias de comunicación”. Gaceta Sanitaria 25(3):179-81. 